Supplement of Geosci. Model Dev., 13, 1513-1544, 2020

https://doi.org/10.5194/gmd-13-1513-2020-supplement

(C) Author(s) 2020. This work is distributed under

the Creative Commons Attribution 4.0 License.

(c) (1)

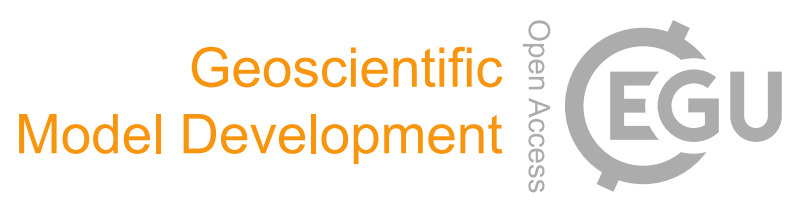

Supplement of

\title{
An intercomparison of tropospheric ozone reanalysis products from CAMS, CAMS interim, TCR-1, and TCR-2
}

Vincent Huijnen et al.

Correspondence to: Vincent Huijnen (vincent.huijnen@ knmi.nl)

The copyright of individual parts of the supplement might differ from the CC BY 4.0 License. 

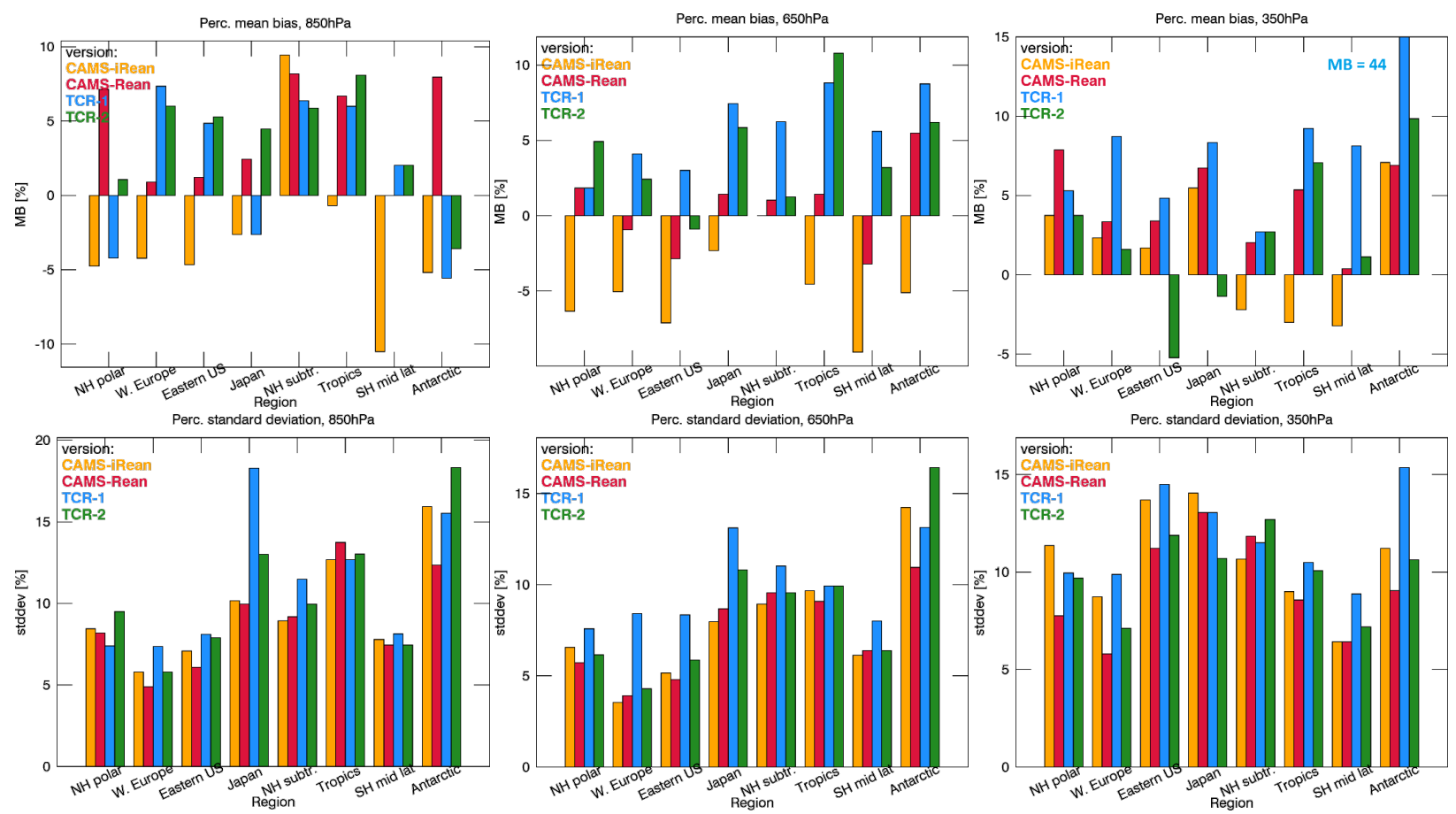

Figure S1. Evaluation of ozone normalized mean bias (reanalysis-observation, top) and standard deviation of difference (bottom) for the four reanalysis products at 850,650 and $350 \mathrm{hPa}$ against sondes, computed for various regions, for the $2005-2016$ time period.
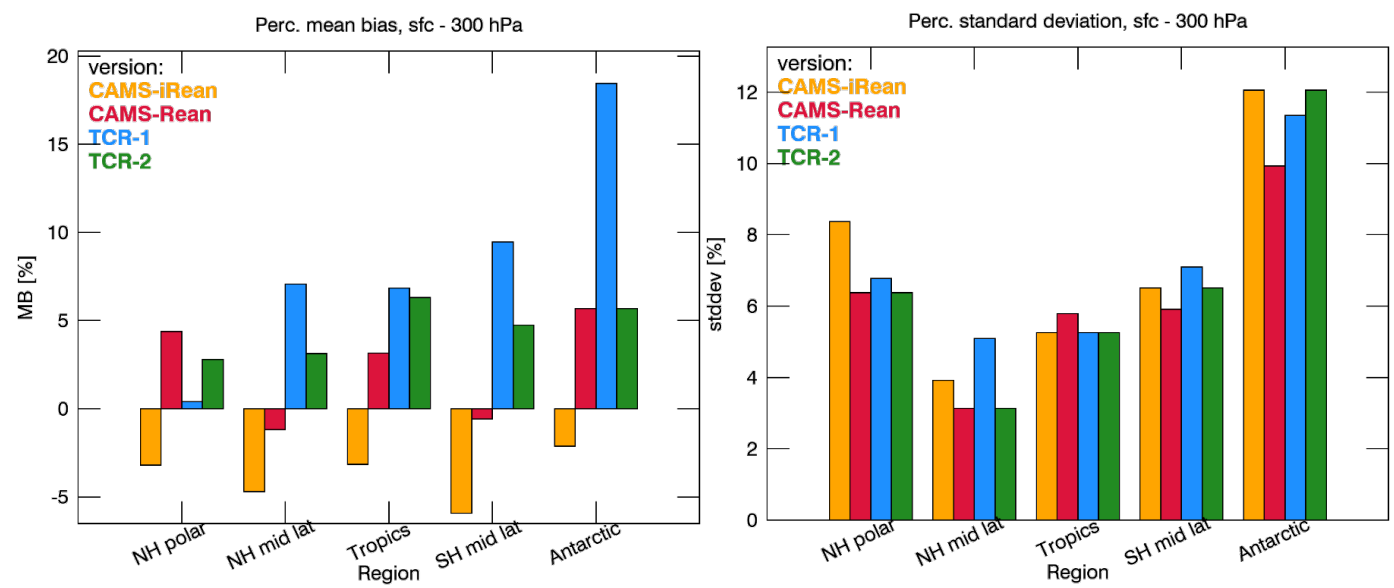

Figure S2. Evaluation of ozone partial columns (surface - $300 \mathrm{hPa}$ ) for the four reanalysis products for the $2005-2016$ time period against sonde observations within five latitude bands. Left: normalized mean bias (reanalysis-observation), right: normalized standard deviation of differences. 


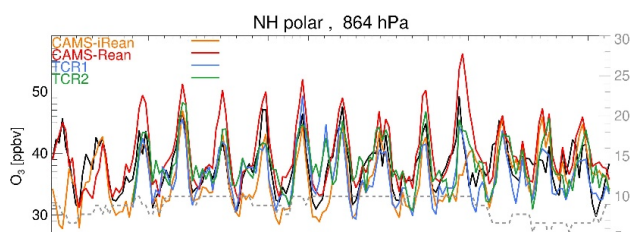
$\begin{array}{lllllllllllllll}20 & 03 & 04 & 05 & 06 & 07 & 08 & 09 & 10 & 11 & 12 & 13 & 14 & 15 & 16\end{array}$

Eestern Europe, $855 \mathrm{hPa}$

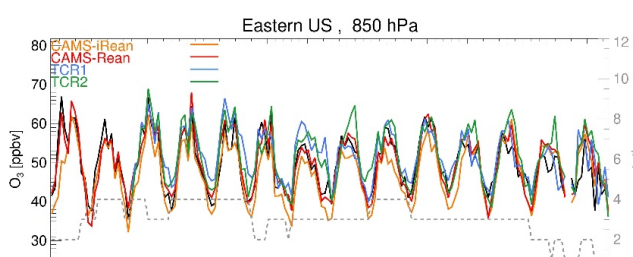

30

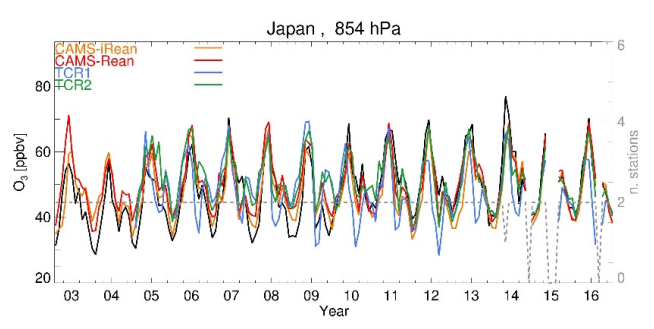

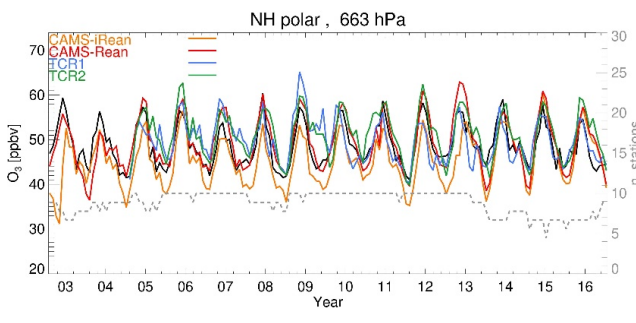
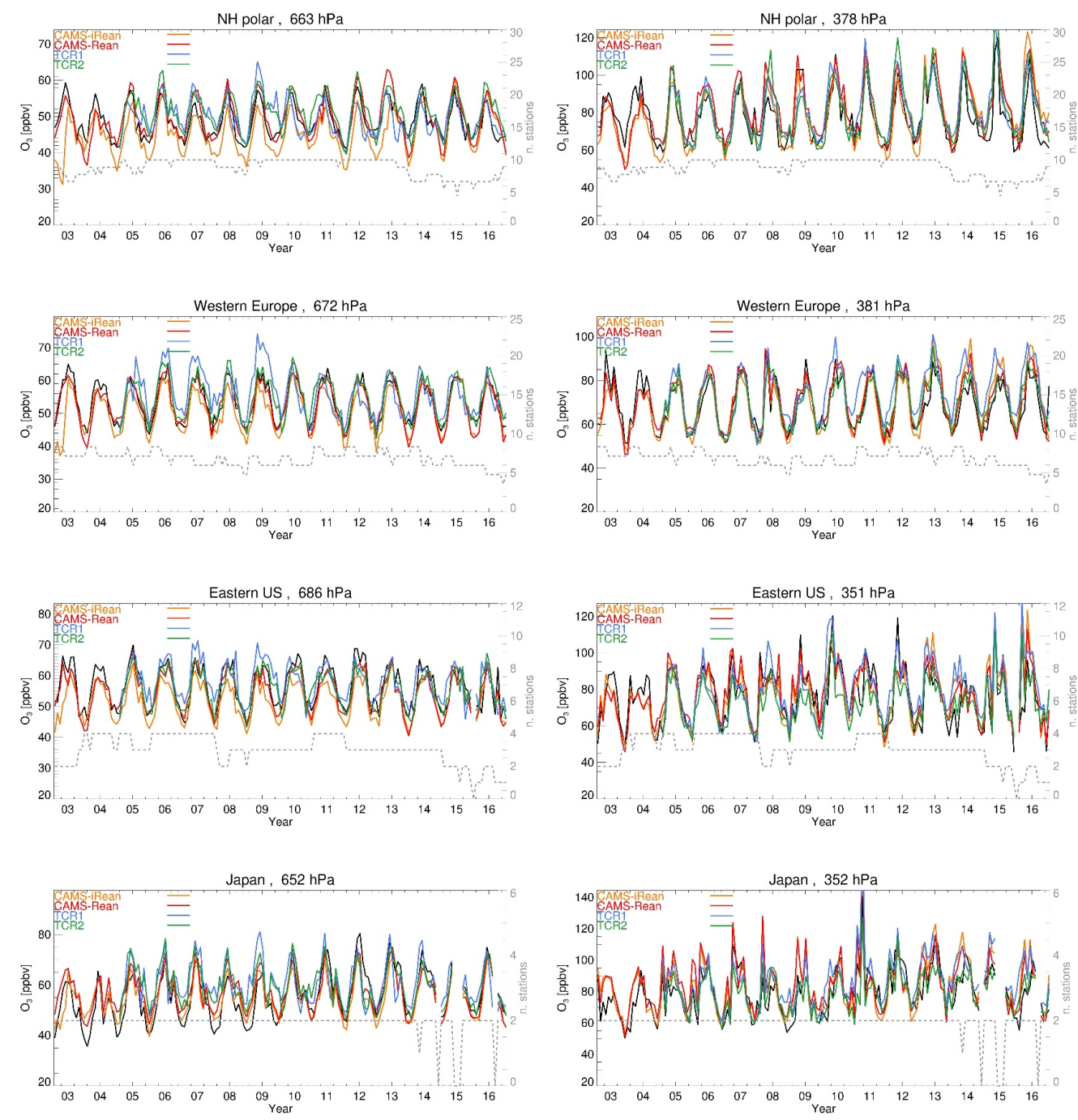

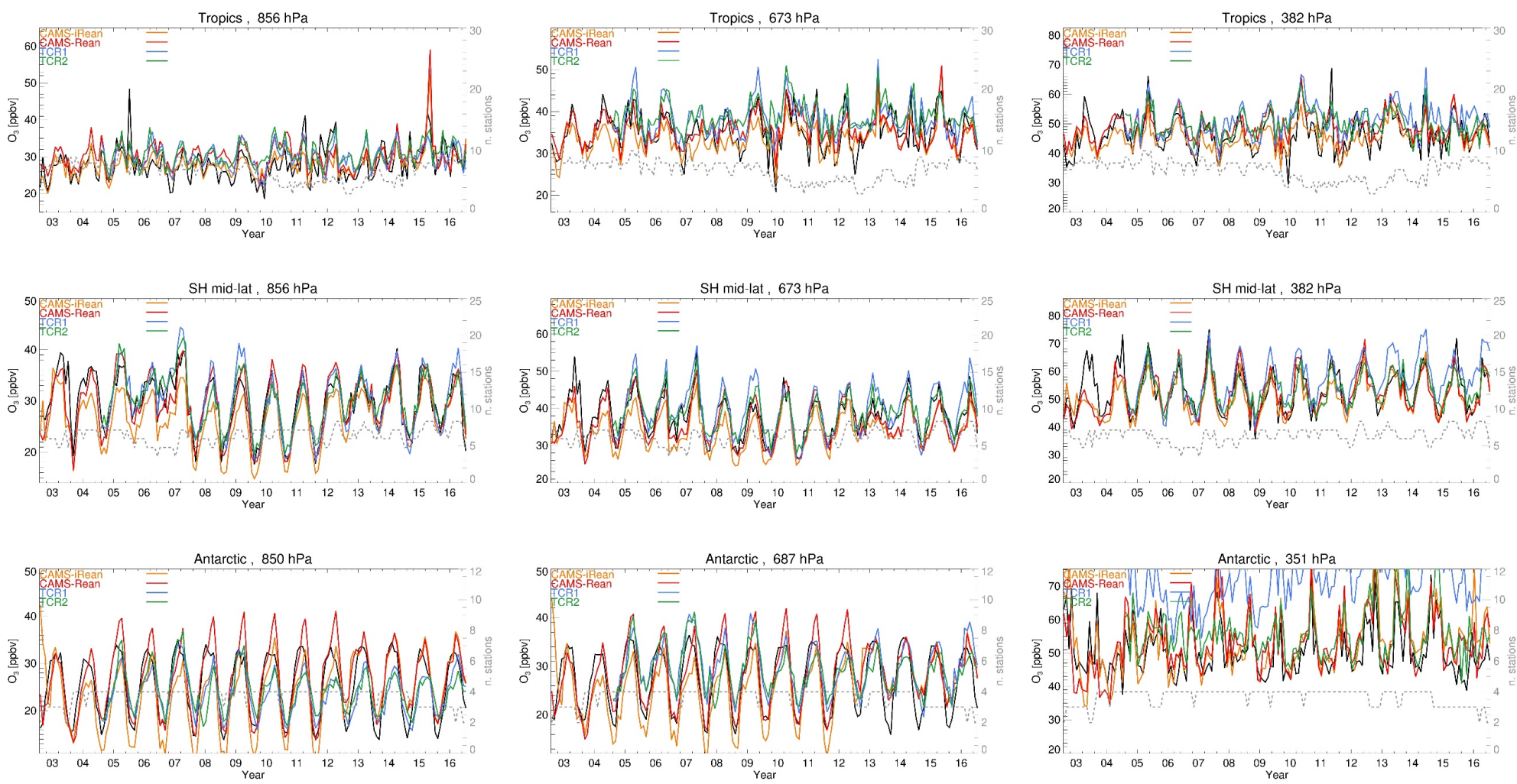

35 Figure S3. Time series of regionally and monthly aggregated ozone concentrations at different altitudes $(850,650$ and $350 \mathrm{hPa})$, sampled at ozone sonde locations, against ozone sonde observations (black). The gray dashed line refers to the number of stations that contribute to the statistics (right vertical axis). 

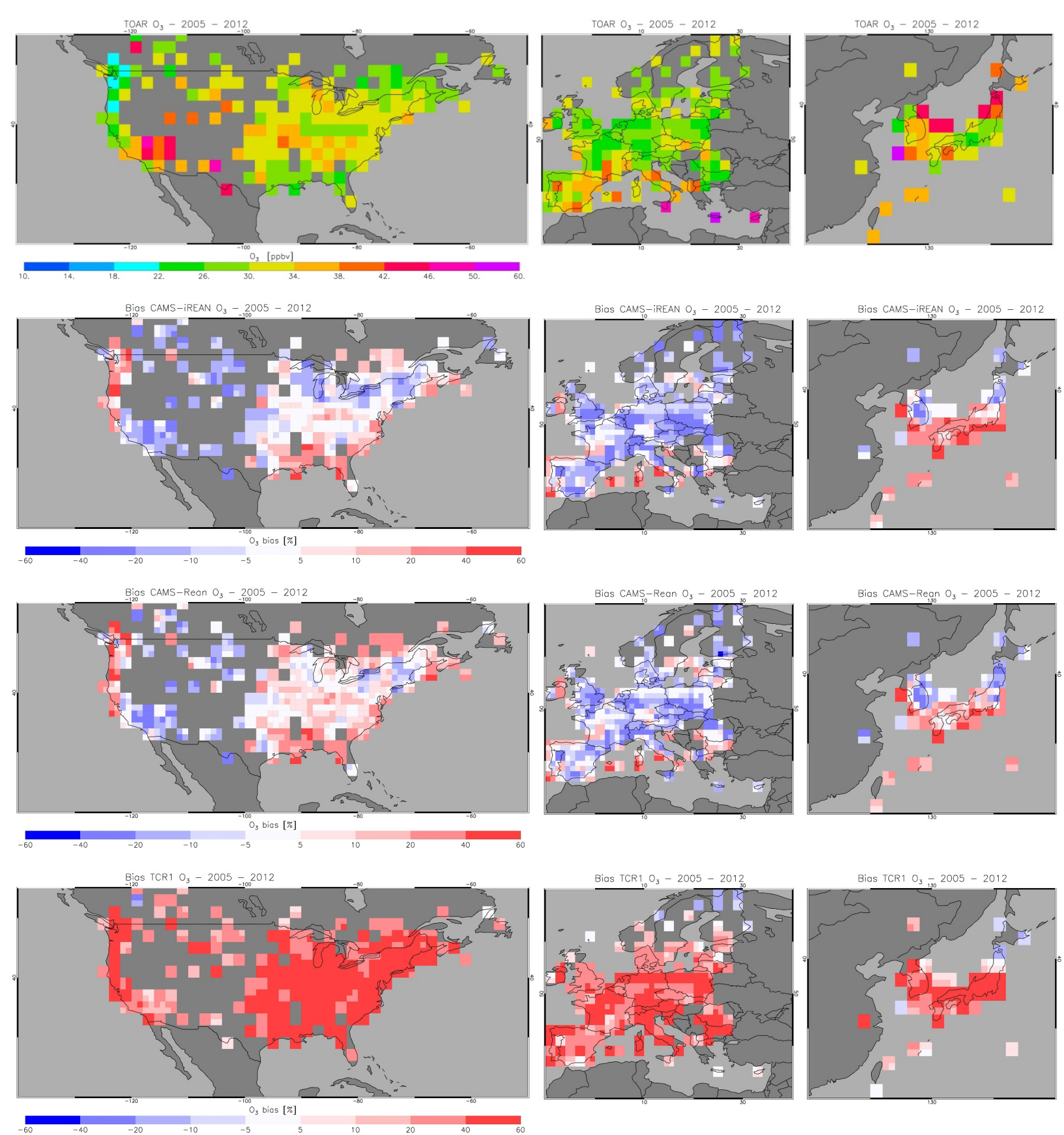

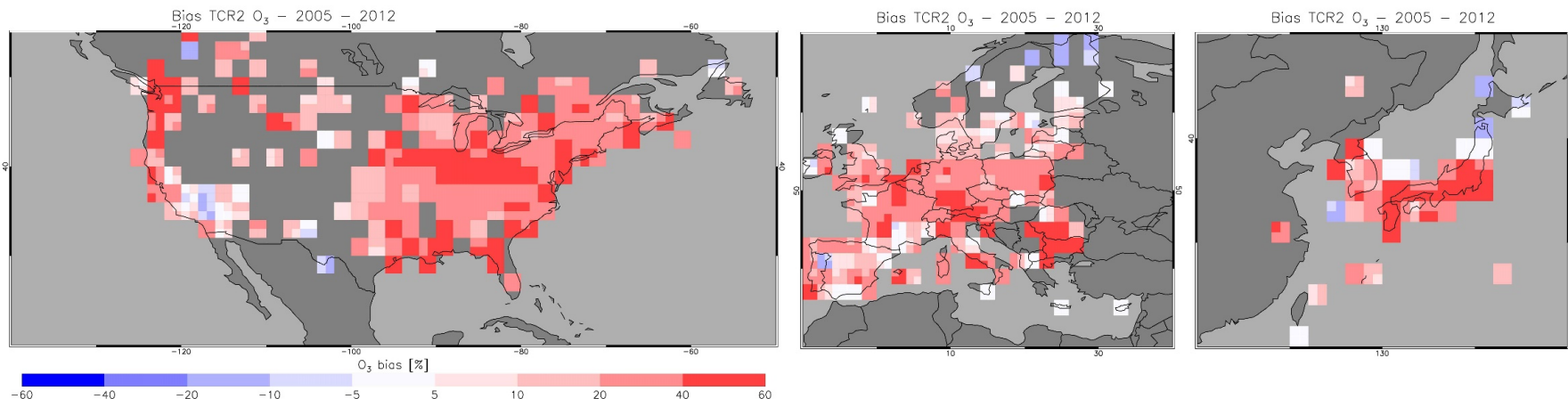

Figure S4: Multi-annual (2005-2012) mean surface ozone from TOAR for three regions, (top figures), along with corresponding relative mean bias (reanalysis-observation) for the reanalyses CAMS-iRean, CAMS-Rean, TCR1 and TCR2, respectively.
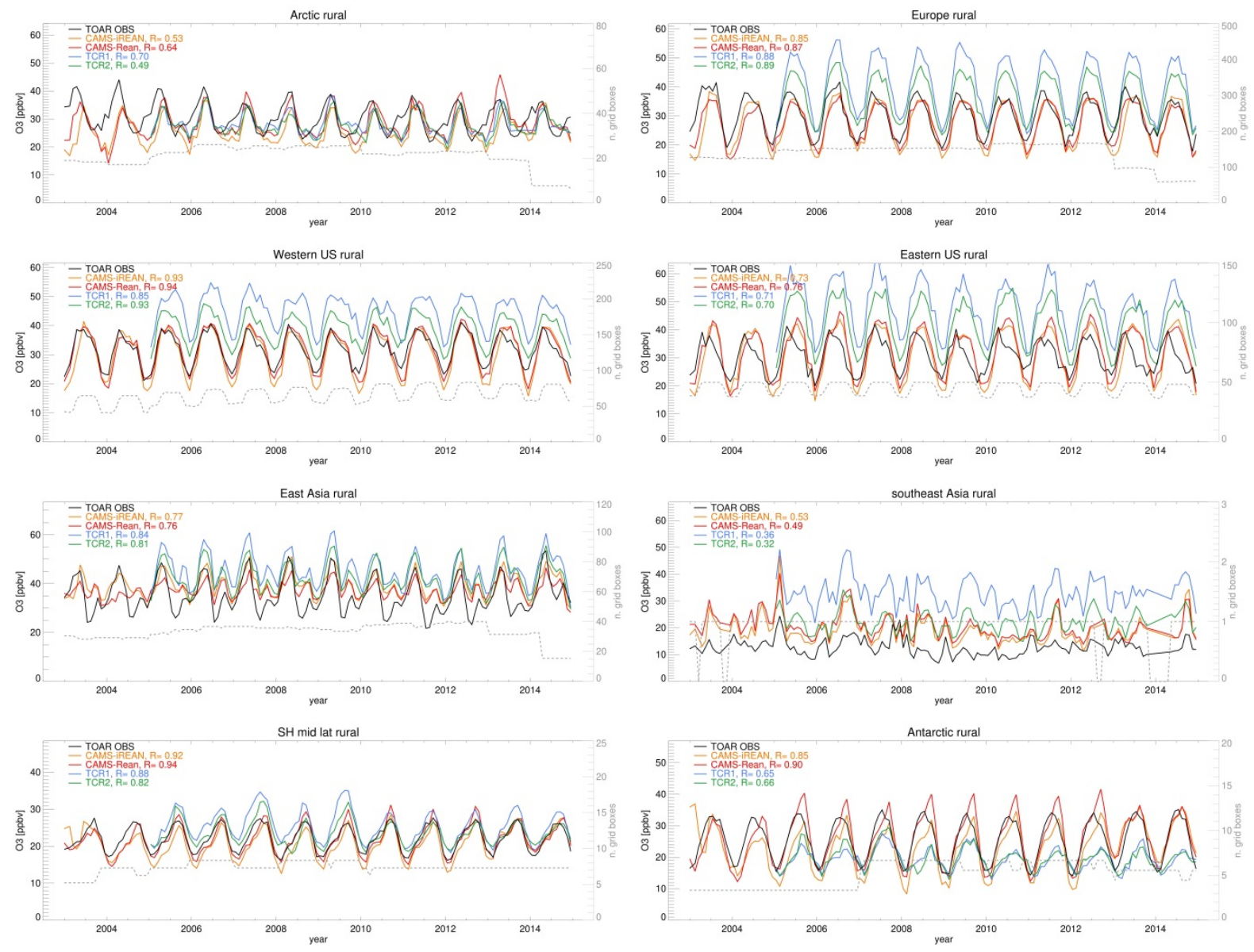

Figure S5: Time series of regional, monthly mean surface ozone against TOAR observations. The dashed line indicates the number of TOAR $2^{\circ} \times 2^{\circ}$ grid boxes contributing to the statistics (see also right axis). Also the temporal correlation for the $2005-2014$ time series is given in the figure legends. 
$\mathrm{O}_{3} \mathrm{PC}$ Arctic, sfc - $300 \mathrm{hPa}$

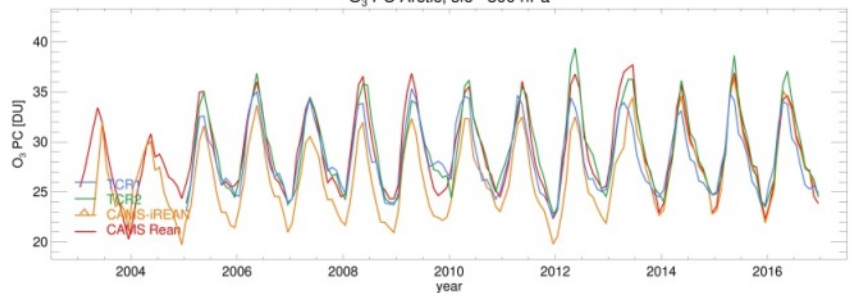

$\mathrm{O}_{3} \mathrm{PC}$ Tropics, sfc - $300 \mathrm{hPa}$

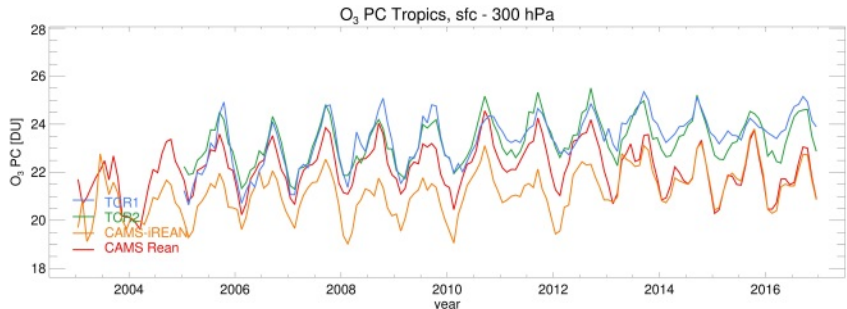

$\mathrm{O}_{3} \mathrm{PC}$ Antarctic, sfc - $300 \mathrm{hPa}$

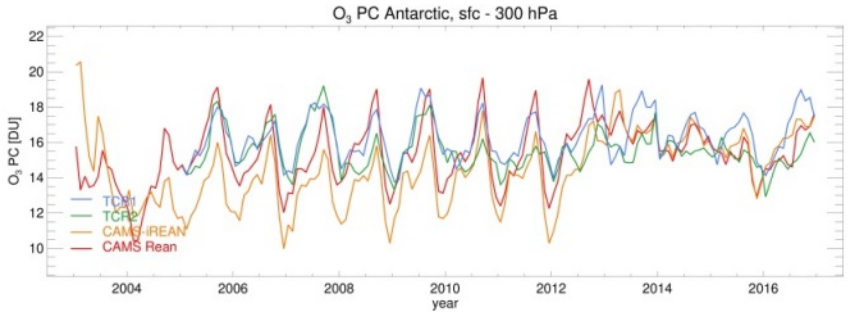

$\mathrm{O}_{3}$ PCNH_midlat, sfc - $300 \mathrm{hPa}$

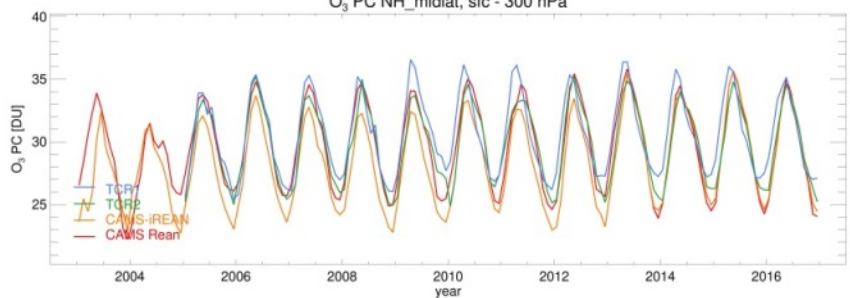

$\mathrm{O}_{3}$ PC SH_midlat, sfc - $300 \mathrm{hPa}$

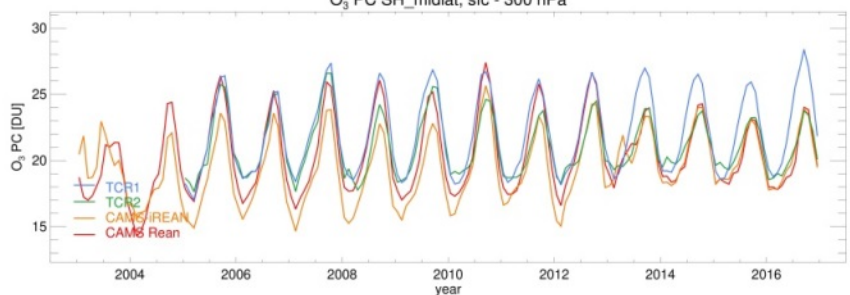

Figure S6: Intercomparison of regionally averaged monthly mean partial columns up to $300 \mathrm{hPa}$.
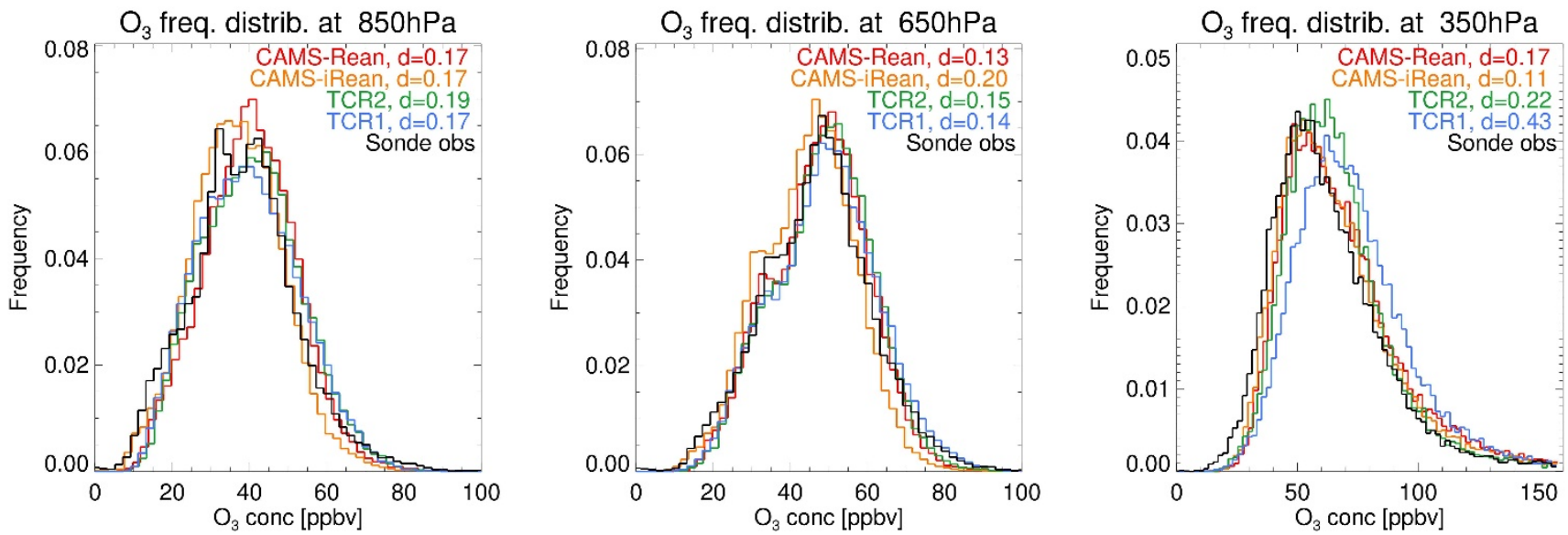

Figure S7: Normalized frequency distributions of $\mathrm{O}_{3}$ mixing ratios sampled at individual ozone sonde observations between 2005 and 2016 at 850 (left), 650 (middle) and $350 \mathrm{hPa}$ (right) for the four reanalyses, together with the corresponding frequency distribution for the observations. The sum of the absolute differences between the frequency distribution of the reanalyses and observations is also given as $d$. 

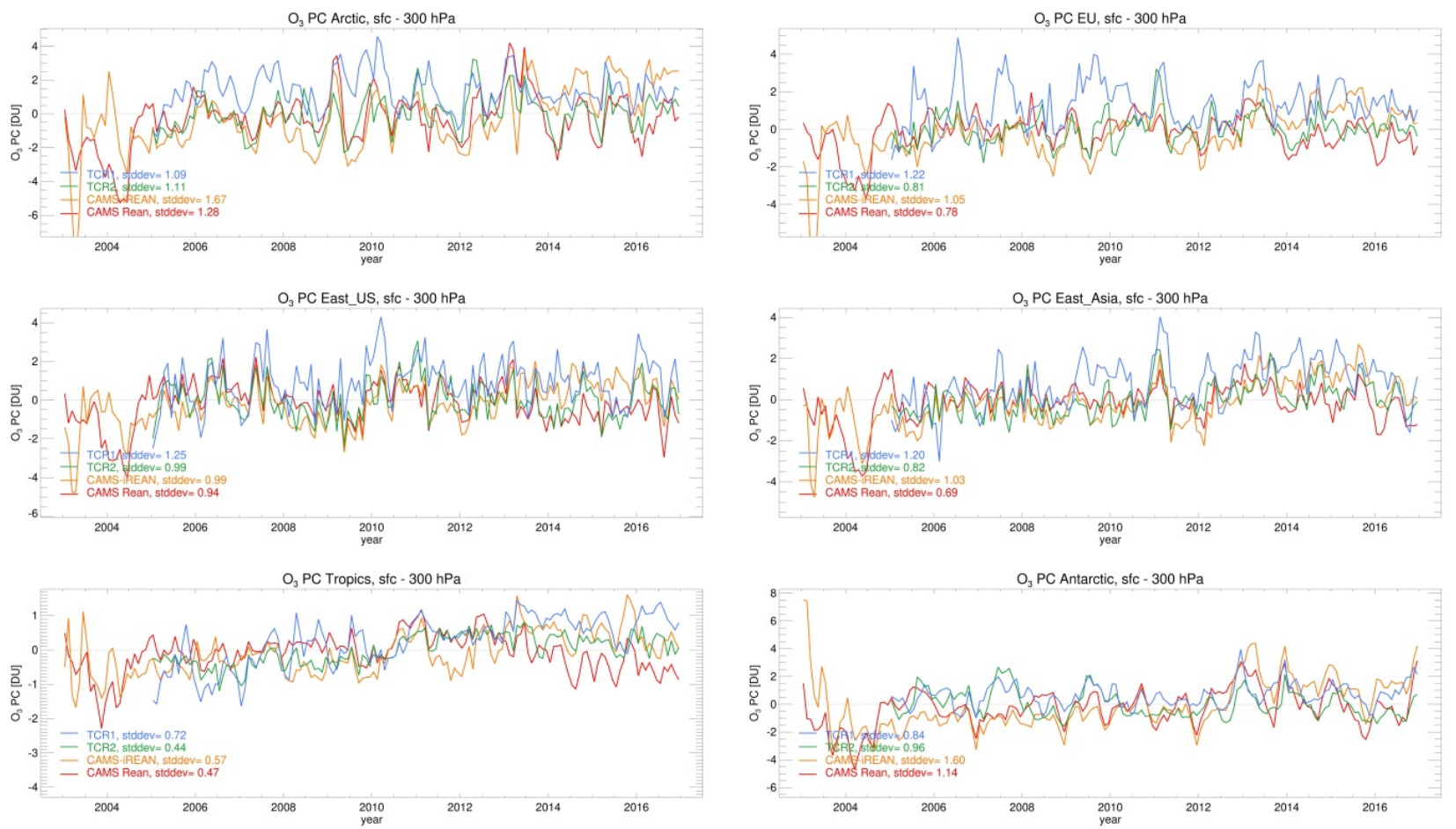

Figure S8: Anomalies in monthly mean $\mathrm{O}_{3}$ partial columns (surface to $300 \mathrm{hPa}$ ) in four reanalyses, averaged for six regions: Arctic $75\left(>60^{\circ} \mathrm{N}\right)$, Eastern US $\left(90^{\circ} \mathrm{W}-7^{\circ} \mathrm{W} ; 3^{\circ} \mathrm{N}-4^{\circ} \mathrm{N}\right)$ Europe $\left(10^{\circ} \mathrm{W}-30^{\circ} \mathrm{E} ; 3^{\circ} \mathrm{N}-60^{\circ} \mathrm{N}\right)$, East Asia $^{\circ}\left(108^{\circ} \mathrm{E}-160^{\circ} \mathrm{E}, 20^{\circ} \mathrm{N}-50^{\circ} \mathrm{N}\right)$, Tropics $^{\circ}$ $\left(30^{\circ} \mathrm{S}-30^{\circ} \mathrm{N}\right)$ and Antarctic $\left(>60^{\circ} \mathrm{S}\right)$. Standard deviations for monthly mean anomalies are given, computed for the $2005-2016$ time period. 
80 Table S1: correlation coefficient $R$ of the interannual variability in tropospheric $O_{3}$ columns between the four reanalyses, as computed for the 2005-2016 monthly mean time series in tropospheric $\mathrm{O}_{3}$ columns from the surface to $300 \mathrm{hPa}$ for different regions, see Figure S8.

\begin{tabular}{|c|c|c|c|c|}
\hline Southeast Asia & CAMS-Rean & CAMS-iRean & TCR-2 & TCR-1 \\
\hline CAMS-Rean & 1.00 & 0.93 & 0.82 & 0.73 \\
\hline CAMS-iRean & & 1.00 & 0.83 & 0.76 \\
\hline TCR-2 & & & 1.00 & 0.90 \\
\hline TCR-1 & & & & 1.00 \\
\hline ENSO_3.4 & CAMS-Rean & CAMS-iRean & TCR-2 & TCR-1 \\
\hline CAMS-Rean & 1.00 & 0.83 & 0.78 & 0.73 \\
\hline CAMS-iRean & & 1.00 & 0.57 & 0.48 \\
\hline TCR-2 & & & 1.00 & 0.77 \\
\hline TCR-1 & & & & 1.00 \\
\hline Arctic & CAMS-Rean & CAMS-iRean & TCR-2 & TCR-1 \\
\hline CAMS-Rean & 1.00 & 0.50 & 0.60 & 0.35 \\
\hline CAMS-iRean & & 1.00 & 0.48 & 0.26 \\
\hline TCR-2 & & & 1.00 & 0.46 \\
\hline TCR-1 & & & & 1.00 \\
\hline Europe & CAMS-Rean & CAMS-iRean & TCR-2 & TCR-1 \\
\hline CAMS-Rean & 1.00 & 0.33 & 0.42 & 0.07 \\
\hline CAMS-iRean & & 1.00 & 0.47 & 0.24 \\
\hline TCR-2 & & & 1.00 & 0.40 \\
\hline TCR-1 & & & & 1.00 \\
\hline Eastern US & CAMS-Rean & CAMS-iRean & TCR-2 & TCR-1 \\
\hline CAMS-Rean & 1.00 & 0.41 & 0.63 & 0.45 \\
\hline CAMS-iRean & & 1.00 & 0.54 & 0.46 \\
\hline TCR-2 & & & 1.00 & 0.64 \\
\hline TCR-1 & & & & 1.00 \\
\hline
\end{tabular}




\begin{tabular}{|l|l|l|l|l|}
\hline Eastern Asia & CAMS-Rean & CAMS-iRean & TCR-2 & TCR-1 \\
\hline CAMS-Rean & 1.00 & 0.52 & 0.52 & 0.29 \\
\hline CAMS-iRean & & 1.00 & 0.69 & 0.55 \\
\hline TCR-2 & & & 1.00 & 0.59 \\
\hline TCR-1 & & & & 1.00 \\
\hline Tropics & CAMS-Rean & CAMS-iRean & TCR-2 & TCR-1 \\
\hline CAMS-Rean & 1.00 & 0.17 & 0.29 & 0.01 \\
\hline CAMS-iRean & & 1.00 & 0.55 & 0.45 \\
\hline TCR-2 & & & 1.00 & 0.73 \\
\hline TCR-1 & & & & 1.00 \\
\hline \multicolumn{1}{|c|}{ Antarctic } & CAMS-Rean & CAMS-iRean & TCR-2 & TCR-1 \\
\hline CAMS-Rean & 1.00 & 0.65 & 0.33 & 0.39 \\
\hline CAMS-iRean & & 1.00 & 0.16 & 0.46 \\
\hline TCR-2 & & & 1.00 & 0.56 \\
\hline TCR-1 & & & & 1.00 \\
\hline
\end{tabular}

